Hendriks SL, van der Merwe, C, Ngidi MS, Manyamba C, Mbele M, Mclntyre M, Molefe QN, Mphephu MN, Mgwane L. (2016). What are we measuring? A comparison of household food security indicators from a sample of households in the Eastern Cape Province, South Africa. Ecology of Food and Nutrition 55:2, 141-162, DOI: 10.1080/03670244.2015.1094063 http://www.tandfonline.com/doi/full/10.1080/03670244.2015.1094063

\title{
What Are We Measuring? Comparison of Household Food Security Indicators in the Eastern Cape Province, South Africa
}

SHERYL L. HENDRIKS*

Institute for Food, Nutrition and Well-being and DST/NRF Centre of Excellence in Food Security, University of Pretoria, South Africa

\author{
CORNÉ VAN DER MERWE \\ School for Information Technology, University of Pretoria, South Africa
}

MJABULISENI S. NGIDI

Department of Agricultural Economics, Extension and Rural Development, University of Pretoria, South Africa CHRISTOPHER MANYAMBA

Department of Agricultural Economics, Extension and Rural Development, University of Pretoria, South Africa MONDLI MBELE

Department of Agricultural Economics, Extension and Rural Development, University of Pretoria, South Africa

\author{
ANGELA M. MCINTYRE
}

Department of Agricultural Economics, Extension and Rural Development, University of Pretoria, South Africa ELIZABETH MKANDAWIRE

Department of Agricultural Economics, Extension and Rural Development, University of Pretoria, South Africa

QUEENETH N. MOLEFE

Department of Agricultural Economics, Extension and Rural Development, University of Pretoria, South Africa

\section{MULALO Q. MPHEPHU}

Department of Agricultural Economics, Extension and Rural Development, University of Pretoria, South Africa

\section{LITHLE NGWANE}

Department of Agricultural Economics, Extension and Rural Development, University of Pretoria, South Africa

*Address correspondence to Sheryl L. Hendriks, Institute for Food, Nutrition and Well-being, University of Pretoria, PBag X20, Hatfield, Pretoria,0028, South Africa. E-mail: sheryl.hendriks@up.ac.za

\begin{abstract}
The development of national food security information systems is constrained by a lack of guidance on which indicators to use. This paper compares food security indicators across two seasons (summer and winter) in one of the most deprived areas
\end{abstract}


of the Eastern Cape province of South Africa. The results show that only anthropometric indicators are sensitive enough to differentiate levels of food insecurity. The lack of consistent classification across indicators means that surveys must use a combination of food consumption and experience of hunger measures backed up by anthropometric measures. Targeting interventions is difficult if the measures cannot be relied on. Further investigation is needed to identify a suite of appropriate indicators for a national information and surveillance system.

KEYWORDS food insecurity, hunger, indicators, food security information system, food security indicators, anthropometric indicators

Improving food security is a priority for South Africa. Data on the status of food insecurity and trends must inform policy, programs and strategies. Yet the country has no reliable and accurate system for analyzing the conditions of the food insecure. It has no up-to-date food insecurity information system. Nor does it have a monitoring and evaluation framework to determine the impact of food security interventions. Although four nationally representative surveys of nutritional status have been conducted since 1994, their sample sizes are quite small and disaggregate data are not publicly available. ${ }^{1}$ The General Household Survey (GHS) collects information from approximately 32000 households annually but does not include nutrition indicators, focusing only on self-reported experience of hunger and access to food.

The Department of Agriculture, Forestry and Fisheries is currently establishing a food security information system and identifying the relevant indicators. The system will provide snapshot surveys, monitoring information, surveillance information, baseline (reference) surveys, scenario planning and forecasts, forecast

\footnotetext{
${ }^{1} 1999$ and 2005 National Food Consumption Surveys (Labadarios 2000; Labadarios et al. 2008), the South African Social SASAS (HSRC 2008) and the recent SANHANES (Shisana et al. 2013).
} 
analyses and rapid assessments (Dlamini 2014). The crucial starting point is to identify the appropriate indicators to include in the surveys and reporting system.

It is internationally recognized that there is no "perfect single measure that captures all aspects of food insecurity" and that food insecurity is not a homogeneous condition easily measured in economic, energy-availability or anthropometric terms (Webb et al. 2006, p. 1405S). Much food security research since the 1974 global food crisis has focused on understanding the causes of food insecurity in a variety of contexts and developing indices for use primarily in distributing development aid. Yet, after decades of discussion and indicator development, we still do not have a universally accepted food security measurement system that we can apply across emergency and non-emergency contexts.

One reason for this is the difficulty we experience in grasping the complexity of food security. If we are to target our interventions effectively, we need to define the experiences, causes and consequences of food insecurity clearly and understand how the multiple dimensions reinforce and compound the problem (Hendriks 2015). Such clarity will help us to predict more accurately who is in need of immediate assistance and who will be adversely affected by shocks, and thus to design more appropriate programs and determine whether our interventions are effective.

A prerequisite for determining the state of food insecurity is to create a scale against which to measure it. Food insecurity is not a single experience but a sequence of stages reflecting increasing deprivation of basic food needs, accompanied by a process of decision making and behavior in response to increasingly constrained household resources. Rather, food security is a continuum of experiences ranging from the most severe form, starvation, to complete food security, defined as a state in which all the FAO (1996) criteria for food security are met and there is no worry 
about future food supply, availability and affordability to meet these criteria. $^{2}$ Moreover, the food (in)security status of an individual or household is not static but dynamic - partly because it is difficult to measure, monitor and evaluate it. Many current assessments do not take this into account, but use once-off ("snapshot") approaches to measurement. Very few take seasonality into account and very little panel data is available.

A number of tools are currently used in international assessments of food insecurity (see Hendriks 2005 and Maxwell, Vaitla, and Coates 2014 for reviews). Indicators are often used interchangeably. In many cases, analyses are based on “arbitrary (or in some cases, institutionalized) selection of single indicators to classify the food insecure" (Maxwell et al. 2014, p. 108). Careful examination of the indicators shows that they do not all measure the same thing; rather, each of them focuses on one or more of the four key elements - availability, access, utilization or nutrition, and stability. This can lead to misestimation and misinterpretation (Coates 2013). However, very few studies have assessed whether common household food security indicator results converge. Maxwell et al. (2014), using data from Ethiopia, show that quite divergent findings can be produced by applying different food security measures to the same dataset. Msaki and Hendriks (2013, 2014) have used Duncan Multiple Range tests to compare the effect of using different indicators to analyze a small sample in South Africa, and bivariate analysis has been applied by Selepe and Hendriks (2014), de Cock et al. (2013) and Faber, Schwabe, and Drimie (2009) in other South African studies and by Gandure, Drimie, and Faber (2010) in a study in Zimbabwe. Fiedler (2013) compares the findings of 24-hour food consumption surveys with those of household consumption and expenditure surveys

\footnotetext{
${ }^{2}$ The World Food Summit defined food security as the "physical and economic access to sufficient, safe and nutritious food to meet ... dietary needs and food preferences for an active healthy life" (FAO, 1996).
} 
and finds they are fairly consistent, but points out that external validity of the studies reviewed is questionable.

This paper compares frequently used indicators of food insecurity, looking at both access to food and nutritional outcomes. The study is broadly based on Maxwell et al.'s. analysis (2014), although it also analyzes adult and child anthropometric measurements (as indicators of nutritional outcomes) and asset ownership (as an indicator of the stability of supply or household resilience). The study compares the indicators from a panel study across two seasons (summer and winter) in one of the most deprived areas of South Africa's Eastern Cape province. The aim was to assess the usefulness of frequently used indicators and compare the results of various food security assessment measures.

\section{FOOD SECURITY MEASUREMENT IN SOUTH AFRICA}

As the Millennium Development Goal era nears its close and indicators are being negotiated for the Sustainable Development Goals, renewed and intensified attention is being paid to finding appropriate food security indicators. There is increasing awareness that the current indicators do not adequately reflect the complexities of food insecurity. At the national level, food security indicators are urgently needed to assess, and improve, the effectiveness of various interventions aimed at reducing poverty and food insecurity and improving nutrition. South Africa's recently approved National Policy on Food and Nutrition Security (Republic of South Africa 2014) recognizes the importance of establishing a national food security information system and commits to the establishment of such a system. 


\section{FOOD SECURITY IN THE STUDY AREA}

This study was conducted in the villages of Dubana and KwaThahle in the Ingquza Hill, in the OR Tambo district of the Eastern Cape. The Ingquza Hill Local Municipality is characterized by widely dispersed traditional rural villages Women, children and youth make up the majority of the population (Table 1). Outmigration in search of labour is high (Ingquza Local Municipality 2013).

TABLE 1 Summary description of the population in Ingquza Hill Local Municipality (Stats SA, 2011)

\begin{tabular}{ll}
\hline Total population & 278,481 \\
Young (0-14) & $42,4 \%$ \\
Working Age (15-64) & $52,2 \%$ \\
Elderly (65+) & $5,4 \%$ \\
Dependency ratio & $91,6 \%$ \\
Unemployment rate & $51,6 \%$ \\
Youth unemployment rate & $60,9 \%$ \\
Average household size & 4,7 \\
Female headed households & $59,1 \%$ \\
\hline
\end{tabular}

Specific local food security data were not available for the community that was the subject of this study, because publicly available data are aggregated at provincial level. The 2013 GHS (Stats SA 2014) reported that 7\% of households in the Eastern Cape had severely inadequate access to food (compared to the national average of $6.1 \%$ ), $22.4 \%$ had inadequate access to food (national average $=17.0 \%$ ) and $70.6 \%$ (national average $=76.9 \%$ ) had adequate access to food. The method used to classify the households in this study is taken from Stats SA (2014, p. 58) and is described in the methods section below. Shisana et al. (2013) reported that only $34 \%$ of Eastern Cape households were classified as food secure through the Community Childhood Hunger Index Program (CCHIP) measure adopted in the 2012 South African National Health and Nutrition Evaluation Survey. A further 32.4\% were classified as "at risk" of hunger and $36.2 \%$ as experiencing hunger, and $5.2 \%$ of the women (over 15 years of age) were underweight, $31.3 \%$ normal weight, $21.7 \%$ overweight and $41.8 \%$ obese (Shisana et al. 2013). 


\section{METHODS}

The data for this study were drawn from a survey of food consumption and production patterns in the poorest rural districts of four provinces (Eastern Cape, KwaZulu-Natal, Limpopo and North West) in South Africa. Two panel surveys were conducted at each site - one in the drier and less agriculturally productive winter months and one in the summer months. This paper reports on data from the OR Tambo district in the Eastern Cape sample, which was surveyed in October 2013 (summer) and July 2014 (winter). The survey captured information about household agricultural production, food consumption, a range of food security indicators, and anthropometric measurements of children between two and 59 months and their female caregivers. Although the district is one of the poorest in the province, there was no widespread food crisis at the time of the survey.

The study site, Ingquza Hill municipality, was selected by means of a multistage sampling process. The poorest districts in the province were selected using a review of socioeconomic indicators. The poorest local municipalities in these districts were then identified using the Heath Systems Trust Deprivation Index (Day et al. 2012). ${ }^{3}$ In OR Tambo district, Port St Johns was identified as the local municipality with the highest proportion of the population that reported experiencing hunger, but it was not considered suitable for the survey because its settlements are sparse due to the undulating terrain. The second most deprived local municipality, Ingquza Hill, was therefore selected.

A multi-stage stratified random sampling technique was applied to identify the sample households. All enumeration area units (EAUs) from the national statistics framework (Stats SA 2003) in the selected municipality that were classified as

\footnotetext{
${ }^{3}$ This index is a measure of relative deprivation of populations. It is derived from a set of demographic and socio-economic variables obtained from the national survey data. Although it is not directly a food security indicator, many of the variables included are also indicators of food insecurity and poverty.
} 
"traditional residential" were listed. Computer-generated random numbers were used to select two EAUs for the study. These were the villages of Dubana and KwaThahle. The sampled households were also drawn, using computer-generated random numbers, from the total number of homesteads in each EAU (obtained from orthophoto maps). The inclusion criterion for households was that there was at least one child aged between 24 and 59 months and the caregiver was present in the homestead and willing to participate in the study.

Quantitative data were collected through household surveys. The Ethics Committee of the university conducting the research granted ethics approval for the study. Caregivers signed a standard informed consent agreement. Enumerators from the communities with at least 12 years of completed education were identified, recruited and trained for the field work. The questions and terminology were translated into the local language in the area.

Numerous food security access indicators were evaluated and compared across the two seasons and compared to "utilization" indicators obtained from anthropometric measurements for children between 24 and 59 months and their female caregivers. The number of assets owned by the household was used as an indicator of stability of access or household resilience (Browne, Ortmann, and Hendriks 2014). Each indicator was estimated according to the following standard procedures set out in the literature.

The Household Dietary Diversity Score (HDDS) (Kennedy, Ballard, and Dop 2011 ) is a measure of dietary quality. It uses a 24-hour recall period of 16 food groups, without asking about frequency of consumption. The dietary diversity score is the sum of the first 14 scores classified as 1 for yes and 0 for no. As this is a 
continuous variable without international cut-offs, it was not classified into categories for this study.

The Food Consumption Score (FCS) (WFP 2006) is an indicator of dietary quantity and quality (diversity). The FCS is the sum of the number of times a food group from the HDDS was eaten in the previous seven-day period, multiplied by the weight (importance in the diet) assigned to each group by the World Food Program (WFP 2006). The scores are then classified into three categories.

The Coping Strategies Index (CSI) was calculated following Maxwell and Caldwell's (2008) method. Data from responses to 15 questions about the frequency of use of precautionary measures applied in the face of food shortages during the previous week were multiplied by the severity ranking for each strategy. ${ }^{4}$ The severity ranking was obtained from focus group discussions held in the community. The higher the CSI, the more food insecure the household was. This variable does not lend itself to categorization.

The Household Hunger Scale (HHS) estimates the proportion of households experiencing three levels of severity of hunger: little or no household hunger (HHS score 0-1), moderate household hunger (HHS score 2-3) and severe household hunger (HHS score 4-6) (Ballard et al. 2011). Respondents were asked how many times in the past month (four weeks) they or any household member went hungry during the day, went to bed hungry or went a whole day and night without food because the household lacked resources to acquire food.

Self-reported experience of hunger (EoH) and modified Complex Access to Food $(\boldsymbol{m C A F})$ questions were used to estimate the incidence of experiences of hunger (self-reported) among adults and children in households during the preceding 12

\footnotetext{
${ }^{4}$ Frequency is calculated as follows: never $=0$; hardly at all or one day a week $=1 ; 1-2$ days a week or once in a while $=2 ; 3-6$ days a week $=5$; and every day $=7$.
} 
months. The EoH and CAF were based on questions typically included in the South African GHS (Stats SA 2012). The EoH questions ask whether any adult or child went hungry in the past 12 months because there was not enough food in the household during that time. The CAF, derived from the Household Food Insecurity Access Scale (HFIAS - Coates, Swindale, and Bilinsky 2007), includes the sum of responses to four questions relating to food access and whether households have experienced these situations more than five times in the past 30 days. As the questions included in the survey did not quite match the questions in the GHS, the modified CAF (mCAF) was calculated using a question about the experience of hunger of adults (mCAFa) and children $(\mathrm{mCAFc})$ in summer. The CAF for winter could not be estimated due to missing data.

The Months of Inadequate Household Food Provision (MIHFP) is a simple sum of the number of months a household reports experiencing hunger in the previous 12 months (after Bilinsky and Swindale 2010).

Anthropometry was used to assess children between 24 and 59 months and their female caregivers. Z-scores for child anthropometry were determined using Antho for Personal Computers (version 3.2.2, WHO 2011) and international reference guidelines. Adult body mass index (BMI) was calculated as the weight of a caregiver divided by her height in centimeters squared.

Household asset ownership was derived as the sum of positive responses to a question about what assets the household owned. Browne et al. (2014) have shown that asset ownership is a useful measure for tracking changes in household resilience over time and can be used to monitor progress towards improved household resilience. A simple sum of categories of assets derived from the Living Standards Measurement question set was calculated. 
Several analyses were carried out in this study to compare the food security measures both within a season (static) and across the two surveys (dynamic). First, the anthropometric indicators were compared to determine consistency in the z-scores of the children and the BMIs of the caregivers. Second, a paired samples t-test was used to compare the indicators for the two surveys to establish whether the households' responses were consistent across the two. Third, the strength of correlations between indicators was assessed for the data from the two surveys. Spearman's rho (often employed for examining non-parametric bivariate relationships) was used to compare indicators. A higher score on the HHS, CSI, MIHFP, EoH and mCAF indicates more frequent experiences of hunger and thus higher food insecurity, whereas higher HDDS and FCS scores indicate greater dietary diversity and food frequency and lower food insecurity. Inverse correlations were expected between some indicators. Pearson's r was used to compare the food security measures and anthropometry. Fourth, where possible the nominal values of the indicators were converted to categorical values using commonly used cut-offs and these values were compared. Finally, the indicators for the FCS and HHS were compared across the two surveys.

The limitations of the small sample size (60 households with 76 children) need to be considered in interpreting the results of the analysis.

\section{RESULTS}

The Nutritional Status of the Sampled Children and Their Caregivers It was found that most of the caregivers were overweight or obese (Table 2), whereas most of the children were stunted (Table 3). The correlations within the adult and child anthropometry scores were highly significant. There was very high correlation between the various measures of child anthropometry but no significant correlation 
between child anthropometry and adult BMI (both the continuous ratio and the classification of the caregivers as underweight, normal, overweight or obese).

TABLE 2 Summary of BMI Classification for Female Caregivers $(\mathrm{n}=$ 76)

\begin{tabular}{lll}
\hline Category & $\begin{array}{l}\text { Qualitative } \\
\text { (WHO 2006) }\end{array}$ & $\begin{array}{l}\text { Adult } \\
(\%)\end{array}$ \\
\hline 1 & $>$ 30 or obese & $\mathbf{4 4 . 7}$ \\
2 & $25-30$ overweight & $\mathbf{3 2 . 9}$ \\
3 & $19-24.9$ normal & $\mathbf{2 1 . 1}$ \\
4 & $<19$ underweight & $\mathbf{1 . 3}$ \\
\hline
\end{tabular}

TABLE 3 Summary of Child Anthropometry (24-59 months)

\begin{tabular}{|c|c|c|c|c|c|c|}
\hline Category & Qualitative label & $\begin{array}{l}\text { BAZ } \\
(\mathrm{n}=55)\end{array}$ & $\begin{array}{l}\text { HAZ } \\
(\mathrm{n}=55)\end{array}$ & $\begin{array}{l}\text { MUACZ } \\
(\mathrm{n}=60)\end{array}$ & $\begin{array}{l}\text { WAZ } \\
(\mathrm{n}=55)\end{array}$ & $\begin{array}{l}\text { WHZ } \\
(\mathrm{n}=55)\end{array}$ \\
\hline & $\begin{array}{l}\text { Coefficient } \\
\text { variance }\end{array}$ & 1.56 & -0.71 & 3.48 & 1.88 & -2.56 \\
\hline 1 & $+2<\mathrm{z} \leq+3 \mathrm{SD}$ & 14.4 & $\mathbf{0}$ & 3.4 & 3.6 & 10.8 \\
\hline 2 & $+1<\mathrm{z} \leq+2 \mathrm{SD}$ & 27.0 & 1.8 & 22.1 & 3.6 & 27.0 \\
\hline 3 & $-1 \mathrm{SD} \leq \mathrm{z} \leq+1 \mathrm{SD}$ & 53.2 & 26.8 & 66.0 & 60.4 & 53.2 \\
\hline 4 & $-2 \mathrm{SD} \leq \mathrm{z}<-1 \mathrm{SD}$ & 1.8 & 33.9 & 8.5 & 27.0 & 1.8 \\
\hline 5 & $-3 \leq \mathrm{z}<-2 \mathrm{SD}$ & 3.6 & 37.5 & $\mathbf{0}$ & 5.4 & 7.2 \\
\hline
\end{tabular}

Half to two-thirds of the children had normal WAZ (weight-for-age), WHZ (weight-for-height), MAZ (BMI-for-age) and MUACZ (MUAC-for-age) z-scores. Twenty-seven per cent of the children were one to two standard deviations below their expected weight-for-age scores but there was a general trend for the same children to be one to two standard deviations above their expected weight-for-height, BMI-for-age and MUAC-for-age scores. The results show a puzzling contradictory pattern between $\mathrm{HAZ}$ and WAZ compared to WHZ, BAZ and MUACZ. One explanation could be that these children had been severely disadvantaged pre- and post-natally (during the first 1000 days). Growth retardation in the first 1000 days has a significant and irreversible impact on development (Smith and Haddad 2015). It is also possible that this retarded growth in early life affects their height-related anthropometry scores later in life. It is well known that malnutrition in early life predisposes adults to higher BMIs (Smith and Haddad 2015). 
A further test was applied to compare the experience of hunger of adults and children (Table 4). Interestingly, the mCAF and EoH of adults and children in summer were significantly correlated but the EoH of adults and children (a binomial) for the winter survey were not significantly related.

TABLE 4 Paired Samples t-Test across Child and Adult Scores

\begin{tabular}{|c|c|c|c|c|c|c|c|c|}
\hline & \multicolumn{5}{|c|}{ Paired differences } & \multirow[t]{3}{*}{$\mathbf{t}$} & \multirow[t]{3}{*}{ df } & \multirow{3}{*}{$\begin{array}{l}\text { Sig. (2- } \\
\text { tailed) }\end{array}$} \\
\hline & \multirow[t]{2}{*}{ Mean } & \multirow[t]{2}{*}{$\begin{array}{c}\text { Std. } \\
\text { deviation }\end{array}$} & \multirow[t]{2}{*}{$\begin{array}{l}\text { Std. } \\
\text { error } \\
\text { mean }\end{array}$} & \multicolumn{2}{|c|}{$\begin{array}{l}95 \% \text { confidence } \\
\text { interval of the } \\
\text { difference }\end{array}$} & & & \\
\hline & & & & Lower & Upper & & & \\
\hline $\begin{array}{l}\text { mCAFc vs } \\
\text { mCAFa }\end{array}$ & -.178 & .628 & .066 & -.309 & -.046 & 2.683 & 89 & .009 \\
\hline $\begin{array}{l}\text { Adult vs } \\
\text { child EoH } \\
\text { summer }\end{array}$ & .1176 & .3907 & .0424 & .0334 & .2019 & 2.776 & 84 & .007 \\
\hline $\begin{array}{l}\text { Adult vs } \\
\text { child EoH } \\
\text { winter }\end{array}$ & .0118 & .1886 & .0205 & -.0289 & .0524 & .575 & 84 & .567 \\
\hline
\end{tabular}

Anthropometry, regarded as one of the few food security related measures that do have scientifically validated international standards, measures the outcomes of food (in)security. Nutrition, reflecting the quality and quantity of food consumed, is only one of these outcomes. One also needs to look at factors affecting the food (un)availability and (in)stability of supply. While this study did not include typical indicators of food supply, asset ownership was included as an indicator of stability or household resilience.

Variability $(\mathrm{CoV})$ in the child anthropometry data showed greater inequality across the sample households than did the food security measures. ${ }^{5}$ The lowest variability was seen for the BMI of caregivers. In the child anthropometry data, the lowest variability was seen for stunting (HAZ), corresponding with the highest level of severe malnutrition in the malnutrition indicators assessed. This finding is consistent with national survey data in South Africa and raises a real concern over

\footnotetext{
${ }^{5}$ The coefficient of variability $(\mathrm{CoV})$ provides insight into the shapes of the distributions and so of the level of inequality among the sample households (Cowell 2009; Maxwell et al. 2014). The higher the $\mathrm{CoV}$, the "flatter" and more unequal the distribution.
} 
how to address severe stunting through effective interventions targeted at babies and young children.

\section{Comparison of Household Food Security across Two Seasons}

A paired samples t-test was used to determine whether there was a significant difference in the food security status of the sampled households across the two surveys. There was significant correlation in the households' food security scores and classification across the two surveys, showing that household responses were consistent across the surveys. The level of consistency was not expected for both the FCS and HHS across the two surveys as there was quite a noticeable increase in these scores in the winter season. There is fairly high homogeneity in consumption patterns among rural households in South Africa, partly due to the equalizing effect of the state welfare payments on which all of the sample households rely.

Do Different Food Security Measures Have Similar Food Security Outcomes?

As the methods section above indicates, food security measures can be used in a continuous scale or as an index of categories (Maxwell et al. 2014). In some cases, categorizing households requires re-coding the initial variable (see Table 5). HDDS, CSI and MIHFP do not have established international cut-offs and so these variables were not categorized.

The coefficient of variance was lower for the food security measures than for the anthropometry. The HHS (a self-reported hunger index) had the highest levels of variance in both surveys. This was followed by the CSI and FCS in the summer survey. The variability in both the CSI and FCS increased in winter. The variability in the CSI can be explained by the fact that the range for this variable is considerable: from 0 to 140 in summer and 0 to 104 in winter. 
Table 6 presents a summary of the Pearson's correlations for anthropometry, household assets and the food security indicators. Table 7 presents the correlations for those measures that could be classified into an index.

The BMI of the caregivers was significantly correlated with the nominal FCS in summer and the HDDS and MIHFP in winter and the binary (food security or food insecure) mCAF for adults in summer. The MUAC z-score was the only child anthropometry measure significantly correlated with any of the nominal, classified and binomial scores. The MUACZ was significantly correlated with the HDDS in both seasons, the FCS in summer and the HHS in winter.

Asset ownership was correlated with the nominal HDDS, FCS, child HoE, mCAFa and mCAFc scores for summer. Asset ownership was significantly correlated with the nominal HDDS and FCS scores in winter, to the classified FCS in both seasons, and to the binary FCS only in summer. 
TABLE 5 Summary of Food Security Indicators

\begin{tabular}{|c|c|c|c|c|c|c|c|}
\hline \multirow[t]{2}{*}{ Index or indicator } & $\begin{array}{l}\text { Sample } \\
\text { size (n) }\end{array}$ & $\begin{array}{l}\text { Coefficient } \\
\text { of variance } \\
(\mathrm{CoV})\end{array}$ & & $\begin{array}{l}\text { Acute food } \\
\text { insecurity }\end{array}$ & $\begin{array}{l}\text { Chronic food } \\
\text { insecurity }\end{array}$ & $\begin{array}{l}\text { Moderate food } \\
\text { insecurity }\end{array}$ & Food secure \\
\hline & & & Criteria & \multicolumn{3}{|c|}{$<19$ underweight } & $>19$ \\
\hline Adult BMI & 76 & 0.24 & BMI classified & \multicolumn{3}{|c|}{$1.3 \%$} & $\begin{array}{c}99.7 \% \text { of which } 44.7 \% \\
\text { are obese }\end{array}$ \\
\hline \multirow{6}{*}{$\begin{array}{l}\text { Anthropometry of children } \\
24-59 \text { months }\end{array}$} & & & Criteria & $-3 \leq z<-2$ SD & $-2 \mathrm{SD} \leq \mathrm{z}<-1 \mathrm{SD}$ & \multicolumn{2}{|r|}{$\geq-1 \mathrm{SD}$} \\
\hline & 55 & 1.56 & $\mathrm{BAZ}$ & $3.6 \%$ & $1.8 \%$ & \multicolumn{2}{|c|}{$94.6 \%$ of which $14.4 \%$ are obese } \\
\hline & 55 & -0.71 & HAZ & $37.5 \%$ & $33.9 \%$ & \multicolumn{2}{|c|}{$28,6 \%$} \\
\hline & 60 & 3.48 & MUACZ & $0 \%$ & $8.5 \%$ & \multicolumn{2}{|c|}{$91.5 \%$} \\
\hline & 55 & 1.88 & WAZ & $5.4 \%$ & $27.0 \%$ & \multicolumn{2}{|c|}{$67.6 \%$} \\
\hline & 55 & -2.56 & WHZ & $7.2 \%$ & $1.8 \%$ & \multicolumn{2}{|c|}{$91.0 \%$} \\
\hline \multirow{3}{*}{$\begin{array}{l}\text { Household Dietary } \\
\text { Diversity Score (HDDS) } 24 \\
\text { hour recall }\end{array}$} & & & Criteria & \multicolumn{3}{|c|}{ Consume $\leq 11$ food groups } & $\begin{array}{c}\text { Consume } 12 \text { or more food } \\
\text { groups }\end{array}$ \\
\hline & 88 & 0.51 & Summer & \multicolumn{3}{|c|}{$96.6 \%$} & $3.4 \%$ \\
\hline & 90 & 0.32 & Winter & \multicolumn{3}{|c|}{$100 \%$} & $0 \%$ \\
\hline \multirow{3}{*}{$\begin{array}{l}\text { Food Consumption Score } \\
\text { (FCS) past } 7 \text { days }\end{array}$} & & & Criteria & \multicolumn{2}{|c|}{ Poor (0-21) } & $\begin{array}{c}\text { Borderline (21.5- } \\
\text { 35) } \\
\end{array}$ & Adequate (> 35) \\
\hline & 89 & 0.74 & Summer & \multicolumn{2}{|c|}{$21.3 \%$} & $13.1 \%$ & $21.3 \%$ \\
\hline & 90 & 0.39 & Winter & \multicolumn{2}{|c|}{$54.3 \%$} & $30.3 \%$ & $12.4 \%$ \\
\hline \multirow{3}{*}{$\begin{array}{l}\text { Coping Strategies Index } \\
\text { (CSI) past } 30 \text { days }\end{array}$} & & & Criteria & \multicolumn{3}{|c|}{$\geq 1$} & $\mathrm{CI}=0$ \\
\hline & 86 & 0.78 & Summer & \multicolumn{3}{|c|}{$92.3 \%$} & $7.8 \%$ \\
\hline & 90 & 0.97 & Winter & \multicolumn{3}{|c|}{$92.3 \%$} & $7.8 \%$ \\
\hline
\end{tabular}




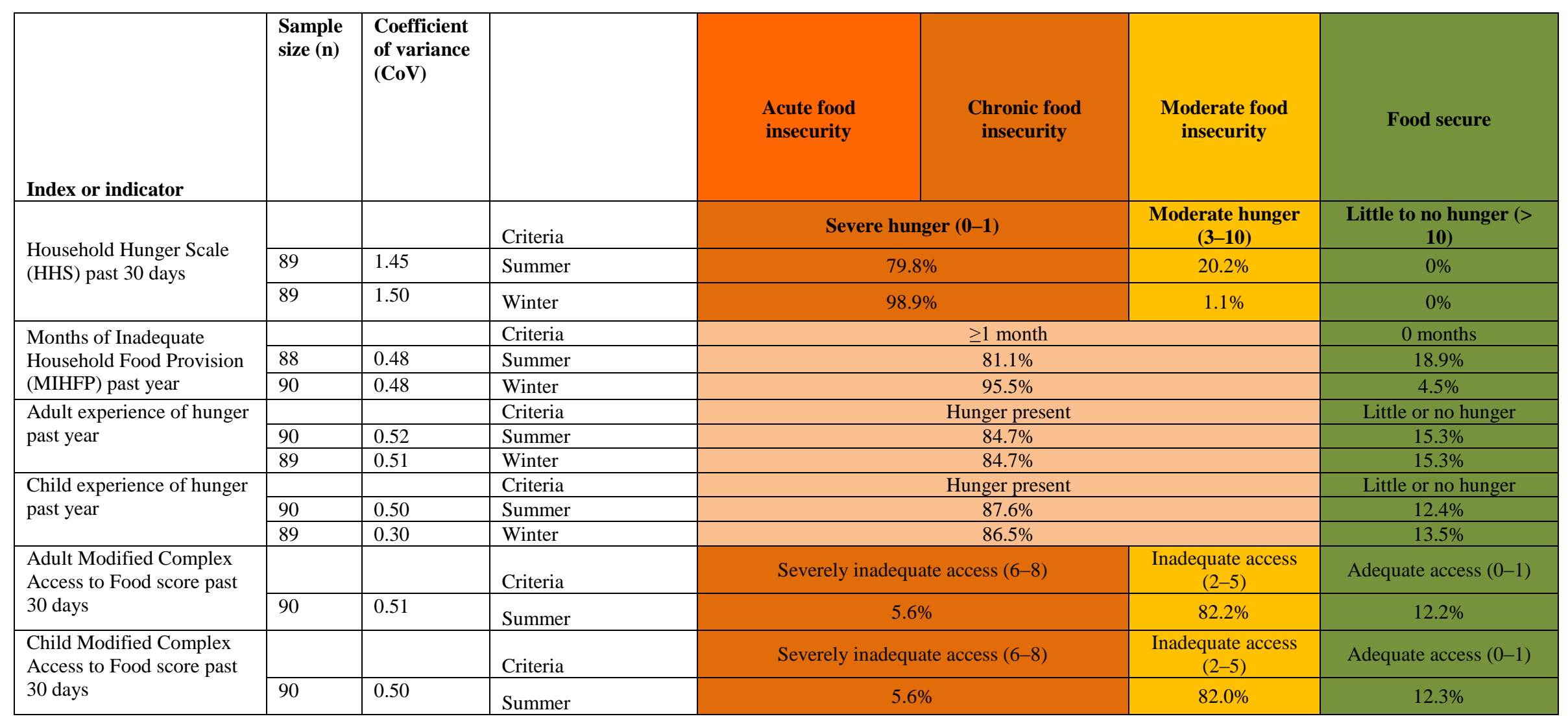


TABLE 6 Spearman's Rho Correlation Coefficients for Nominal Scores

\begin{tabular}{|c|c|c|c|c|c|c|c|c|c|c|}
\hline $\begin{array}{l}\text { Food security } \\
\text { measure }\end{array}$ & Season & HDDS & $\overline{F S C}$ & CSI & HHS & MIHFP & $\begin{array}{l}\text { Adult } \\
\text { EoH }\end{array}$ & $\begin{array}{l}\text { Child } \\
\text { EoH }\end{array}$ & $\mathrm{mCAFc}$ & $\mathrm{mCAFa}$ \\
\hline \multirow{2}{*}{$\begin{array}{l}\text { BMI of } \\
\text { caregivers }\end{array}$} & Summer & 0.220 & $0.274^{*}$ & -0.134 & 0.121 & 0.187 & -0.002 & -0.113 & -0.056 & 0.116 \\
\hline & Winter & $0.234^{*}$ & 0.198 & 0.082 & 0.010 & $-0.230^{*}$ & -0.151 & -0.150 & - & - \\
\hline \multirow[t]{2}{*}{ BAZ } & Summer & -0.015 & -0.003 & 0.003 & 0.158 & -0.116 & -0.241 & -0.215 & -0.041 & 0.094 \\
\hline & Winter & 0.032 & 0.007 & -0.062 & -0.158 & -0.256 & -0.220 & -0.248 & - & - \\
\hline \multirow{2}{*}{ HAZ } & Summer & 0.078 & -0.027 & -0.106 & 0.003 & -0.046 & 0.112 & 0.133 & -0.120 & -0.090 \\
\hline & Winter & 0.246 & 0.210 & 0.051 & 0.070 & 0.050 & 0.202 & 0.121 & - & - \\
\hline \multirow[t]{2}{*}{ MUACZ } & Summer & $0.286^{*}$ & $0.344^{* * *}$ & -0.104 & 0.129 & 0.148 & -0.204 & -0.129 & -0.076 & -0.020 \\
\hline & Winter & $0.325^{*}$ & 0.251 & -0.038 & -0.111 & -0.071 & -0.100 & -0.134 & - & - \\
\hline \multirow[t]{2}{*}{ WAZ } & Summer & 0.116 & 0.161 & -0.025 & $0.273^{*}$ & 0.038 & -0.059 & -0.039 & 0.032 & 0.113 \\
\hline & Winter & 0.158 & 0.124 & 0.091 & 0.055 & -0.030 & 0.005 & -0.088 & - & - \\
\hline \multirow[t]{2}{*}{ WHZ } & Summer & 0.015 & 0.026 & -0.019 & 0.150 & -0.115 & -0.233 & -0.188 & -0.006 & 0.111 \\
\hline & Winter & 0.040 & 0.032 & -0.048 & -0.132 & -0.240 & -0.195 & -0.231 & - & - \\
\hline \multirow[t]{2}{*}{ Assets } & Summer & $0.333^{* * *}$ & $0.212^{*}$ & -0.077 & 0.018 & -0.067 & -0.202 & $-0.215^{*}$ & $-0.374^{* *}$ & $-0.288^{* *}$ \\
\hline & Winter & $0.314^{* *}$ & $0.332^{* * *}$ & -0.121 & -0.198 & -0.172 & -0.051 & -0.047 & ser. & (1) \\
\hline \multirow[t]{2}{*}{ HDDS } & Summer & 1.000 & $0.855^{\text {*** }}$ & -0.076 & $-0.305^{* * *}$ & -0.121 & $-0.231^{*}$ & -0.145 & -0.052 & -0.102 \\
\hline & Winter & 1.000 & $0.626^{* *}$ & $-0.288^{* *}$ & -0.099 & 0.031 & 0.028 & 0.035 & - & - \\
\hline \multirow[t]{2}{*}{ FSC } & Summer & $0.855^{* *}$ & 1.000 & -0.155 & -0.166 & -0.099 & $-0.268^{*}$ & -0.208 & 0.011 & -0.024 \\
\hline & Winter & $0.626^{* *}$ & 1.000 & $-0.213^{*}$ & $-0.338^{* *}$ & -0.143 & -0.199 & -0.132 & (2) & - \\
\hline \multirow[t]{2}{*}{ CSI } & Summer & -0.076 & -0.155 & 1.000 & -0.134 & -0.124 & 0.071 & -0.046 & -0.133 & -0.110 \\
\hline & Winter & $-0.288^{*}$ & $-0.213^{*}$ & 1.000 & $0.487^{* *}$ & $0.286^{* *}$ & $0.320^{* * *}$ & $0.232^{*}$ & 0.70 & - \\
\hline \multirow[t]{2}{*}{ HHS } & Summer & $-0.305^{* *}$ & -0.166 & -0.134 & 1.000 & $0.338^{* * *}$ & 0.153 & 0.119 & 0.180 & $0.269^{*}$ \\
\hline & Winter & -0.099 & $-0.338^{* *}$ & $0.487^{* *}$ & 1.000 & $0.249^{*}$ & $0.649^{* *}$ & $0.544^{* *}$ & - & - \\
\hline \multirow[t]{2}{*}{ MIHFP } & Summer & -0.121 & -0.099 & -0.124 & $0.338^{* *}$ & 1.000 & 0.156 & 0.046 & 0.209 & $0.256^{*}$ \\
\hline & Winter & 0.038 & -0.143 & $0.286^{* *}$ & $0.249^{*}$ & 1.000 & $0.285^{* *}$ & 0.201 & - & - \\
\hline \multirow[t]{2}{*}{ Adult EoH } & Summer & $-0.231^{*}$ & $-0.268^{*}$ & 0.071 & 0.153 & 0.156 & 1.000 & $0.842^{* *}$ & $0.419^{* *}$ & $0.418^{* *}$ \\
\hline & Winter & 0.035 & -0.132 & $0.232^{*}$ & $0.544^{* *}$ & 0.201 & $0.860^{* *}$ & 1.000 & 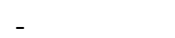 & . \\
\hline \multirow[t]{2}{*}{ Child EoH } & Summer & -0.145 & -0.208 & -0.046 & 0.119 & 0.046 & $0.842^{* * *}$ & 1.000 & $0.479^{* *}$ & $0.424^{* * *}$ \\
\hline & Winter & 0.028 & -0.199 & $0.320^{* * *}$ & $0.649^{* *}$ & $0.285^{* * *}$ & $0.860^{* * *}$ & 1.000 & o. & - \\
\hline mCAFc & Summer & -0.052 & 0.011 & -0.133 & 0.180 & 0.209 & $0.419^{* *}$ & $0.479^{* * *}$ & 1.000 & $0.915^{* *}$ \\
\hline $\mathrm{mCAFa}$ & Summer & -0.102 & -0.024 & -0.110 & $0.269^{*}$ & $0.256^{*}$ & $0.418^{* * *}$ & $0.424^{* *}$ & $0.915^{* *}$ & 1.000 \\
\hline
\end{tabular}

*. Correlation is significant at the 0.05 level (2-tailed).

**. Correlation is significant at the 0.01 level (2-tailed). 
TABLE 7 Spearman's Rho Correlation Coefficients for Classified and Binomial Scores

\begin{tabular}{|c|c|c|c|c|c|c|c|c|c|c|}
\hline \multirow[t]{2}{*}{ Indicator } & \multirow[t]{2}{*}{ Season } & \multicolumn{5}{|c|}{ Classified measures } & \multicolumn{4}{|c|}{ Binary measures } \\
\hline & & FCS & HHS & $\begin{array}{c}\text { Adult } \\
\text { BMI }\end{array}$ & mCAFc & mCAFa & mCAFc & mCAFa & FCS & HHS \\
\hline \multirow{2}{*}{$\begin{array}{l}\text { Adult } \\
\text { BMI } \\
\text { nominal }\end{array}$} & Summer & -0.075 & -0.011 & $\overline{-}^{-}$ & -0.034 & -0.043 & $-0.257^{*}$ & -0.154 & -0.064 & -0.011 \\
\hline & Winter & -0.212 & 0.193 & $\overline{-}^{-}$ & - & - & - & - & -0.001 & 0.193 \\
\hline \multirow{3}{*}{$\begin{array}{l}\text { Adult } \\
\text { BMI } \\
\text { classified } \\
\text { BAZ }\end{array}$} & Summer & 0.083 & 0.017 & 10.000 & 0.047 & 0.064 & 0.209 & 0.121 & 0.099 & 0.017 \\
\hline & Winter & 0.149 & 0.119 & 10.000 & 0.047 & 0.064 & 0.209 & 0.121 & -0.061 & 0.119 \\
\hline & $\begin{array}{r}\text { Summer } \\
\text { Winter }\end{array}$ & $\begin{array}{c}0.125 \\
-0.080\end{array}$ & $\begin{array}{c}-0.065 \\
0.123\end{array}$ & $\begin{array}{l}-0.110 \\
-0.110\end{array}$ & $\begin{array}{l}-0.060 \\
-0.060\end{array}$ & $\begin{array}{l}-0.060 \\
-0.060\end{array}$ & $\begin{array}{l}-0.075 \\
-0.075\end{array}$ & $\begin{array}{l}-0.075 \\
-0.075\end{array}$ & $\begin{array}{c}0.120 \\
-0.014\end{array}$ & $\begin{array}{c}-0.065 \\
0.123\end{array}$ \\
\hline HAZ & $\begin{array}{r}\text { Summer } \\
\text { Winter }\end{array}$ & $\begin{array}{l}-0.011 \\
-0.247\end{array}$ & $\begin{array}{c}-0.033 \\
0.104\end{array}$ & $\begin{array}{l}-0.095 \\
-0.095\end{array}$ & $\begin{array}{l}0.129 \\
0.129\end{array}$ & $\begin{array}{l}0.114 \\
0.114\end{array}$ & $\begin{array}{l}-0.164 \\
-0.164\end{array}$ & $\begin{array}{l}-0.073 \\
-0.073\end{array}$ & $\begin{array}{c}0.062 \\
-0.159\end{array}$ & $\begin{array}{l}-0.033 \\
0.104\end{array}$ \\
\hline MUACZ & $\begin{array}{r}\text { Summer } \\
\text { Winter }\end{array}$ & $\begin{array}{l}-0.186 \\
-0.255^{*}\end{array}$ & $\begin{array}{c}-0.182 \\
0.108\end{array}$ & $\begin{array}{l}-0.223 \\
-0.223\end{array}$ & $\begin{array}{l}-0.010 \\
-0.010\end{array}$ & $\begin{array}{l}-0.024 \\
-0.024\end{array}$ & $\begin{array}{l}-0.177 \\
-0.177\end{array}$ & $\begin{array}{l}-0.177 \\
-0.177\end{array}$ & $\begin{array}{l}-0.173 \\
-0.043\end{array}$ & $\begin{array}{c}-0.182 \\
0.108\end{array}$ \\
\hline WHZ & $\begin{array}{r}\text { Summer } \\
\text { Winter }\end{array}$ & $\begin{array}{c}0.095 \\
-0.092\end{array}$ & $\begin{array}{l}-0.072 \\
0.119\end{array}$ & $\begin{array}{l}-0.106 \\
-0.106\end{array}$ & $\begin{array}{l}-0.082 \\
-0.082\end{array}$ & $\begin{array}{l}-0.082 \\
-0.082\end{array}$ & $\begin{array}{l}-0.084 \\
-0.084\end{array}$ & $\begin{array}{l}-0.084 \\
-0.084\end{array}$ & $\begin{array}{l}0.092 \\
0.000\end{array}$ & $\begin{array}{c}-0.072 \\
0.119\end{array}$ \\
\hline WAZ & $\begin{array}{r}\text { Summer } \\
\text { Winter }\end{array}$ & $\begin{array}{c}0.000 \\
-0.108\end{array}$ & $\begin{array}{c}-0.230 \\
0.077\end{array}$ & $\begin{array}{l}-0.124 \\
-0.124\end{array}$ & $\begin{array}{l}-0.155 \\
-0.155\end{array}$ & $\begin{array}{l}-0.155 \\
-0.155\end{array}$ & $\begin{array}{l}-0.077 \\
-0.077\end{array}$ & $\begin{array}{l}-0.077 \\
-0.077\end{array}$ & $\begin{array}{c}-0.003 \\
0.087\end{array}$ & $\begin{array}{r}-0.230 \\
0.077\end{array}$ \\
\hline Assets & $\begin{array}{r}\text { Summer } \\
\text { Winter }\end{array}$ & $\begin{array}{l}-0.230^{*} \\
-0.242^{*}\end{array}$ & $\begin{array}{l}0.101 \\
0.147\end{array}$ & $\begin{array}{l}-0.185 \\
-0.185\end{array}$ & $\begin{array}{l}0.172 \\
0.172\end{array}$ & $\begin{array}{l}0.167 \\
0.167\end{array}$ & $\begin{array}{l}0.147 \\
0.147\end{array}$ & $\begin{array}{l}0.085 \\
0.085\end{array}$ & $\begin{array}{l}-0.247^{*} \\
-0.186\end{array}$ & $\begin{array}{l}0.101 \\
0.147\end{array}$ \\
\hline \multirow[t]{2}{*}{$\begin{array}{l}\text { HDDS } \\
\text { nominal }\end{array}$} & Summer & ${ }^{-}$ & $0.265^{*}$ & -0.158 & 0.091 & 0.070 & -0.002 & -0.042 & ${ }^{-}$ & $0.265^{*}$ \\
\hline & Winter & $0.643^{* * *}$ & 0.095 & -0.173 & 0.185 & $0.255^{*}$ & -0.004 & 0.091 & $0.383^{* * *}$ & 0.095 \\
\hline \multirow[t]{2}{*}{$\begin{array}{l}\text { FSC } \\
\text { nominal }\end{array}$} & Summer & $0.851^{* *}$ & 0.147 & -0.224 & 0.080 & 0.112 & 0.061 & -0.020 & $0.832^{* * *}$ & 0.147 \\
\hline & Winter & $0.862^{* *}$ & 0.100 & -0.166 & 0.138 & 0.146 & -0.031 & 0.013 & $\overline{-}^{-}$ & 0.100 \\
\hline FCS & Summer & 1.000 & -0.194 & 0.083 & -0.155 & -0.164 & -0.179 & -0.082 & $0.977^{* * *}$ & -0.194 \\
\hline classified & Winter & 1.000 & -0.109 & 0.149 & -0.108 & -0.105 & 0.100 & 0.076 & $0.683^{* *}$ & -0.109 \\
\hline Binary & Summer & $0.977^{* * *}$ & -0.180 & 0.099 & -0.182 & -0.158 & -0.183 & -0.045 & 1.000 & -0.180 \\
\hline FCS & Winter & $0.683^{* *}$ & 0.040 & -0.061 & 0.012 & 0.032 & 0.095 & 0.114 & 1.000 & 0.040 \\
\hline CSI & $\begin{array}{r}\text { Summer } \\
\text { Winter }\end{array}$ & $\begin{array}{l}0.118 \\
0.064\end{array}$ & $\begin{array}{l}0.128 \\
0.164\end{array}$ & $\begin{array}{c}0.192 \\
-0.060\end{array}$ & $\begin{array}{c}-0.165 \\
-0.391^{* *}\end{array}$ & $\begin{array}{l}-0.145 \\
-0.447^{* *}\end{array}$ & $\begin{array}{l}-0.113 \\
-0.165\end{array}$ & $\begin{array}{l}-0.033 \\
-0.236^{*}\end{array}$ & $\begin{array}{l}0.131 \\
0.265^{*}\end{array}$ & $\begin{array}{l}0.128 \\
0.164\end{array}$ \\
\hline HHS & Summer & $0.246^{*}$ & $-0.772^{* *}$ & -0.150 & $-0.230^{*}$ & -0.159 & $-0.224^{*}$ & -0.122 & 0.208 & - \\
\hline
\end{tabular}




\begin{tabular}{|c|c|c|c|c|c|c|c|c|c|c|}
\hline \multirow[t]{2}{*}{ Indicator } & \multirow[t]{2}{*}{ Season } & \multicolumn{5}{|c|}{ Classified measures } & \multicolumn{4}{|c|}{ Binary measures } \\
\hline & & FCS & HHS & $\begin{array}{c}\text { Adult } \\
\text { BMI }\end{array}$ & mCAFc & mCAFa & mCAFc & mCAFa & FCS & HHS \\
\hline \multirow[t]{2}{*}{ nominal } & & & & & & & & & & $0.772^{* * *}$ \\
\hline & Winter & 0.193 & $-0.216^{*}$ & -0.051 & $-0.361^{* *}$ & $-0.301^{* *}$ & $-0.379^{* * *}$ & $-0.341^{* * *}$ & $0.242^{*}$ & $-0.216^{*}$ \\
\hline \multirow{4}{*}{$\begin{array}{l}\text { HHS } \\
\text { classified } \\
\text { Binary } \\
\text { HHS }\end{array}$} & Summer & -0.194 & 1.000 & 0.017 & $0.210^{*}$ & 0.166 & $0.242^{*}$ & 0.165 & -0.180 & $1.000^{* *}$ \\
\hline & Winter & -0.109 & 1.000 & 0.119 & 0.016 & 0.009 & -0.026 & -0.031 & 0.040 & $1.000^{* *}$ \\
\hline & Summer & -0.194 & $1.000^{* *}$ & 0.017 & $0.210^{*}$ & 0.166 & $0.242^{*}$ & 0.165 & -0.180 & 1.000 \\
\hline & Winter & $0.277^{* *}$ & $1.000^{* *}$ & 0.119 & 0.016 & 0.009 & -0.026 & -0.031 & 0.040 & 1.000 \\
\hline \multirow[t]{2}{*}{ MiAFP } & Summer & 0.210 & $-0.408^{* *}$ & -0.103 & $-0.230^{*}$ & $-0.290^{* * *}$ & -0.140 & -0.193 & 0.183 & $0 . \overline{408}^{* * *}$ \\
\hline & Winter & 0.180 & -0.030 & $0.259^{*}$ & -0.175 & -0.197 & -0.006 & -0.101 & $0.221^{*}$ & -0.030 \\
\hline \multirow{4}{*}{$\begin{array}{l}\text { Adult } \\
\text { EoH } \\
\text { Child } \\
\text { EoH }\end{array}$} & Summer & $0.245^{*}$ & $-0.276^{*}$ & -0.067 & $-0.297^{* * *}$ & $-0.290^{* * *}$ & $-0.369^{* * *}$ & $-0.333^{* *}$ & $0.236^{*}$ & $-0.276^{*}$ \\
\hline & Winter & 0.195 & $-0.257^{*}$ & 0.071 & $-0.291^{* *}$ & $-0.252^{*}$ & $-0.311^{* *}$ & $-0.229^{*}$ & $0.323^{* *}$ & $-0.257^{*}$ \\
\hline & Summer & 0.206 & $-0.300^{* * *}$ & 0.029 & $-0.342^{* * *}$ & $-0.292^{* *}$ & $-0.409^{* * *}$ & $-0.299^{* *}$ & 0.208 & $0300^{* * *}$ \\
\hline & Winter & 0.152 & $-0.270^{*}$ & 0.042 & $-0.292^{* *}$ & $-0.255^{*}$ & $-0.332^{* *}$ & $-0.251^{*}$ & $0.252^{*}$ & $-0.270^{*}$ \\
\hline \multirow{6}{*}{$\begin{array}{l}\text { mCAFc } \\
\text { nominal } \\
\text { mCAFc } \\
\text { classified } \\
\text { mCAFc } \\
\text { binary } \\
\text { mCAFa } \\
\text { nominal } \\
\text { mCAFa } \\
\text { classified } \\
\text { mCAFa } \\
\text { binary }\end{array}$} & Summer & 0.010 & $-0.318^{* * *}$ & 0.047 & $-0.685^{* *}$ & $-0.695^{* *}$ & $-0.409^{* *}$ & $-0.466^{* *}$ & 0.017 & $0 . \overline{31}^{* *}$ \\
\hline & Summer & -0.155 & $0.210^{*}$ & 0.047 & 1.000 & $0.884^{* *}$ & $0.597^{* *}$ & $0.525^{* *}$ & -0.182 & $0.210^{*}$ \\
\hline & Summer & -0.179 & $0.242^{*}$ & 0.209 & $0.597^{* *}$ & $0.556^{* *}$ & 1.000 & $0.835^{* *}$ & -0.183 & $0.242^{*}$ \\
\hline & Summer & 00.029 & $\begin{array}{c}- \\
00.339^{* *}\end{array}$ & $\begin{array}{c}- \\
00.092\end{array}$ & $\begin{array}{c}- \\
00.659^{* *}\end{array}$ & $-0.715^{* *}$ & $-0.401^{* *}$ & $-0.476^{* *}$ & 0.039 & $0.339^{* *}$ \\
\hline & Summer & -0.164 & 0.166 & 0.064 & $0.884^{* *}$ & 1.000 & $0.556^{* *}$ & $0.666^{* *}$ & -0.158 & 0.166 \\
\hline & Summer & -0.082 & 0.165 & 0.121 & $0.525^{* *}$ & $0.666^{* * *}$ & $0.835^{* *}$ & 1.000 & -0.045 & 0.165 \\
\hline
\end{tabular}

*. Correlation is significant at the 0.05 level (2-tailed).

**. Correlation is significant at the 0.01 level (2-tailed). 
As expected, the HDDS and FCS were significantly related. As mentioned above, the HDDS is derived from a 24-hour food consumption recall and the FCS from a seven-day dietary recall. Both the nominal HDDS and the FCS were correlated with the CSI in winter, the nominal HDDS was correlated with the nominal HHS in summer and the nominal FCS with the nominal HHS in winter. There was no evidence of a clearly consistent pattern of correlation between the consumption and hunger measures.

The CSI was not correlated with any indicators in the summer. This could be due to the wide range of scores in summer and the fact that there is no classification system for this indicator. However, in winter the CSI was significantly correlated with the nominal HHDS, FCS, HHS, MIHFP, Adult EoH and child EoH.

The HHS was significant related to more measures than the consumption scores (HDDS and FCS) were. The nominal HHS was significantly related to the nominal HDDS in summer, the nominal FCS and CSI in winter, the MIHFP (in both seasons), child and adult $\mathrm{EoH}$ in winter and the nominal mCAFa in summer.

The MIHFP was related to the CSI in winter, the nominal HHS (in both seasons) and the nominal mCAFa in summer. However, the MIHFP was only significantly correlated with child experience of hunger (MCAFc, a binary measure). in winter In the case of the classified scores, the MIHFP was related to the classified HHS, mCAFa and mCAFc and binary HHS.

The EoH variable was a binomial derived from a question about whether adults and children had experienced hunger. While adult EoH was correlated with a number of food security measures, the relationships were inconsistent across the seasons and significantly related to the nominal HHDS, FCS and other hunger related measures (child $\mathrm{EoH}$ and $\mathrm{mCAFa}$ and $\mathrm{mCAFc}$ ). The adult $\mathrm{EoH}$ was related to the CSI and 
nominal HHS in winter. The only variable that the EoH was not significantly related to in either season was the MIHFP. The adult EoH was significantly related to the classified FCS, HHS, mCAFa, mCAFc and all four binary measures (mCAFa, mCAFc, FCS and HHS) in summer. The same pattern emerged for winter, except that the adult EoH was not related to the classified FCS in winter.

The child $\mathrm{EoH}$ was statistically significantly related to the nominal $\mathrm{mCAFc}$ and mCAFa in summer and with the HHS. But, as with the adult EoH, the child EoH was related to the nominal CSI and HHS in winter as well as the MIHFP. Correlation between the EoH and the mCAF was expected as the $\mathrm{EoH}$ is derived from the mCAF. However, the $\mathrm{EoH}$ and mCAF scores, derived from including the question on adult hunger (mCAFa) and that with child hunger $(\mathrm{mCAFc})$, did not behave in the same way. As would be expected, the nominal $\mathrm{mCAFa}$ and $\mathrm{mCAFc}$ were both related to the adult and child EoH in both summer and winter. The nominal mCAFa and mCAFc were strongly correlated. Child EoH behaved in a similar manner to the adult score for this measure, except that child EoH was not correlated with the classified FCS in either season.

The nominal mCAFa and mCAFc were not correlated with the nominal scores of the consumption indicators, but the adult score was correlated with the nominal HHS. The number of significant correlations for this measure increased when converted into classified and binary measures and compared to the other classified food security measures. The nominal, classified and binary mCAFc and the nominal mCAFa were significantly related to the classified and binary HHS. This is not unexpected, as both scores draw on questions from the HFIAS (Coates et al. 2007).

As Table 6 shows, different measures indicate different levels of food (in)security. The proportion of food insecure households shown by the FCS is lower 
than that shown by the HHS and EoH. The difference is likely to be in part due to the recall period used - the FCS asks for a week's recall, the HHS for a month's recall and the EoH for a 12-month recall - and the different things the measures investigate - the FCS asks about food consumption, whereas the other two measures ask about experience of hunger. In its binary form, food secure or food insecure, the HHS rates all the sampled households as food insecure. This raises concern about the accuracy of this measure. The HHS relies on the last three questions of the HFIAS, which are about extreme experiences of hunger. The HFIAS is intended for use in emergency contexts. The present study was not conducted during a food emergency and in fact widespread access to social protection provides grant income to all the households in this sample. Although these grants may not be sufficient to eliminate hunger, they have had considerable success in reducing poverty in South Africa (Hendriks, 2014). The HHS finding that all the sampled houses are insecure is also inconsistent with the findings of the $\mathrm{EoH}$ and the FSC. The $\mathrm{EoH}$ shows that $85 \%$ or more adults and children experienced hunger in summer and winter based on a question asked in the GHS. When disaggregated into severely inadequate and inadequate complex access to to food (as asked in the same GHS), we found that $5.6 \%$ of adults and children experienced severely inadequate access to food more than five times in 30 days in October 2013 (summer). Comparative data were not available for winter. Eighty-two per cent of adults and children experienced inadequate access to food more than five times in the previous 30 days. The FSC shows an even less extreme finding with $21.3 \%$ of households classified as food secure in summer. The proportion of food insecure households with poor and borderline FCS scores increased in winter, with only $12.4 \%$ falling into the food security category in winter. Both these measures are more sensitive than the HHS. Although the CSI was not able to classify the 
households into food secure categories, only $7.8 \%$ of households did not use the precautionary strategies in both seasons.

\section{CONCLUSION}

The study findings show differences between summer and winter in household food consumption scores, although the differences were not found to be statistically significant. However, shifts towards lower dietary diversity and more widely reported episodes of hunger are evident in winter.

The complex problem of undernutrition and overweight is clearly evident. However, the anomalous situation of very high levels of child stunting, a tendency to overweight among the same subset of children, and a significant proportion of overweight and obese caregivers demands closer investigation and urgent action to identify and address the underlying causes.

The results of the study show how careful one needs to be in selecting and reporting on food security indicators. Food security and hunger data are extremely sensitive political information and should be used to direct resources and assistance towards those who most need support in overcoming deprivation. If they are not accurate, such data could overestimate a community's needs and dilute food security intervention efforts.

The results show that it is essential to use not only measures that reflect the situation according to reports of consumption and experience of hunger but also measures that reflect the outcomes of food insecurity, i.e. anthropometric measures. In this study the anthropometric measures identified a small number of children with faltering growth. These children need immediate attention and must be referred to a 
health care facility and brought to the attention of social welfare officials for direct intervention.

High levels of stunting among children may be indicative of early food deprivation or a disadvantaged start to life that could have included low birth weight, ill health or inappropriate feeding practices, among many other factors. Although stunting levels are high in South Africa, the findings of this study concur with those of national studies with regard to levels of overweight among children.

Although most of the children's weight-for-age scores indicated that they could be food secure, over $90 \%$ of the children in the study had acceptable BMI, MUAC and weight-for-height z-scores, indicating adequate consumption - at least in terms of energy consumption. Although anthropometric measures are the most accurate measures of current overall nutritional status, they are not an accurate indicator of dietary quality.

Dietary diversity was generally inadequate among the sampled households. This indicator and the FCS index derived from it were sensitive enough to show seasonal changes in dietary quality. The CSI is not able to classify households along the food security continuum and the levels of severity of each strategy included in the survey must therefore be established through community engagement. This makes the CSI unsuitable for comparative national surveys but very helpful for understanding households' precautionary strategies. Such information is vital in designing appropriate intervention programs.

The HHS, MIHFP and experience of hunger are self-reported perceptions and subject to misreporting and respondent interpretation. The experience of hunger is not universal and perceptions of what constitutes being hungry differ according to context, culture and experience. Stats SA's complex access to food score is unique to 
the GHS but also based on self-reported experience. Self-reported measures of the experience of hunger were exceptionally high among the sampled households and at odds with the anthropometric findings.

Generally, the sampled households are not starving but their diets are inadequate and intervention is needed. Consumption indicators reflect the quality of diet but do not tell us much about the adequacy of consumption. Measures of experience of hunger reflect the presence and frequency of deprivation but do not tell us anything about the quality of the diet or the effects of deprivation. Anthropometric measures assess the cumulative effect of previous food consumption and health but do not tell us much about the quality of the diet, which is necessary for planning intervention. None of these measures provides insight into the causes of food insecurity.

Most measures are not sensitive enough to identify those in most need of support, and the inconsistent classifications of a single household produced by different measures make targeting assistance difficult. It is clear that a variety of indicators are needed to monitor changes in the food security situation but none on its own is adequate to classify households as food secure or food insecure. When using the anthropometric indicators, to assume that adults and children with measurements above "normal" are food secure would be a terrible mistake. Even overweight people could be food insecure and thus in need of assistance.

It is clear that the measures included in the current South African GHS are useful but not sufficient to adequately record and monitor the food security situation in the country. Anthropometric scores are expensive to collect, but it is essential to include them in food security assessments. Government should therefore actively capture child height and weight measurements by making it statutory to register baby 
clinic records in a national directory. This will enable monitoring of stunting at an early age and provide an opportunity to intervene at an appropriate stage in a child's development. National surveys should at a minimum include MUAC and body mass measurements for small children and BMIs for caregivers.

Dietary diversity should be included in as many as possible of the South African surveys intended to measure, monitor and assess food insecurity. In this study the FCS was able to classify households by dietary quality and identify those in need of assistance. However, this tool was developed for use in food emergency contexts. Development of a similar context-specific FCS is recommended, to complement the self-reported hunger score used by Stats SA. Development of such an FCS would require careful examination of the consumption patterns and dietary behavior associated with typical diets and categorization of thresholds that will identify households with inadequate diet quality. The questionnaire for assessing dietary diversity is fairly simple and quick to administer and can be used to derive an appropriate FCS. However, a limitation of the HDDS and the FCS is that they use only short recall periods (respectively 24 hours and seven days).

Panel surveys are valuable, though expensive and often not feasible. This study, limited to data from only two separate months, succeeded in demonstrating seasonal changes in consumption. It used the HHS and mCAF, with a recall period of 30 days, and the CSI and MIHFP, with a recall period of a year. Yet these may not be sensitive enough to capture seasonal variations in food insecurity levels and severity if only used in a once-off survey. And as noted, the HHS was designed for emergency contexts and may over-estimate hunger in the South African context. It is therefore recommended that the use of the CAF is continued. 
However, an additional tool is needed to bring together the CSI questions in a way that will enable categorization of households according to the severity of precautionary strategies commonly adopted in the face of real or anticipated food shortages. The questions should take cognizance of the temporal (weekly, monthly and seasonal) dimensions of food shortages faced by South African households.

The South African food security information system aims to provide snapshot surveys, monitoring information, surveillance information, baseline (reference) surveys, scenario planning and forecasts, forecast analyses and rapid assessments. It is therefore essential that it include a bank of core indicators while more appropriate indicators are being tested and developed. Ongoing analysis will be necessary, not only of the data but also of the appropriateness and reliability of the indicators used.

\section{ACKNOWLEDGEMENTS}

This article is based on work that was part of a research project funded by the South African Water Research Commission (WRC Project No. Project K5/2172/4), the South African National Research Foundation (Grant numbers CPR20110706000020, 77053 and 80529), the University of Pretoria's Institutional Research Theme on Food, Nutrition and Well-being, and the University of Pretoria's Post-Doctoral Fellowship Programme. However, the authors accept responsibility for any opinions, findings, conclusions and recommendations contained in this article.

\section{REFERENCES}

Ballard, T., J. Coates, A. Swindale, and M. Deitchler. 2011. Household hunger scale: Indicator definition and measurement guide. Washington, DC: Food and Nutrition Technical Assistance II Project (FANTA). 
Bilinsky, P., and A. Swindale. 2010. Months of adequate household food provisioning (MAHFP) for measurement of household food access: Indicator guide. Version 4. Washington, DC: Food and Nutrition Technical Assistance II Project (FANTA).

Browne, M., G.F. Ortmann, and S.L. Hendriks. 2014. Developing a resilience indicator for food security monitoring and evaluation. Agrekon 53 (2): 25-46.

Coates, J. 2013. Build it back better: Deconstructing food security for improved measurement and action. Global Food Security 2:188-194.

Coates, J., A. Swindale, and P. Bilinsky. 2007 Household Food Insecurity Access Scale (HFIAS) for measurement of household food access: Indicator guide (v. 2). Washington, DC: Food and Nutrition Technical Assistance, Academy for Educational Development.

Cowell, F.A. 2009. Measuring Inequality. Oxford: Philip Allan.

de Cock, N., M. D’Haese, N. Vink, C.J. van Rooyen, L. Staelens, H.C. Schönfeldt, and L. D'Haese. 2013. Food security in rural areas of Limpopo province, South Africa. Food Security 5: 269-282.

Day, C., P. Barron, N. Massyn, A. Padarath, and R. English, (2012). The District Health Barometer 2010/2011. Durban: Health Systems Trust, Durban.

Dlamini, T. 2014. Presentation of the proposed South African Vulnerability Assessment Committee (SAVAC) Work Plan for 2015. Presentation at the SAVAC Technical Resource Team meeting, 1 December 2014, Department of Agriculture, Forestry and Fisheries, Pretoria.

Faber, M., C. Schwabe, and S. Drimie. 2009. Dietary diversity in relation to other household food security indicators. International Journal of Food Safety, Nutrition and Public Health 2: 1-15.

FAO. 1996. World Food Summit: Rome Declaration on World Food Security. Rome: Food and Agriculture Organization.

Fiedler, J.L. 2013. Towards overcoming the food consumption information gap: Strengthening household consumption and expenditures surveys for food and nutrition policy making. Global Food Security 2:56-63.

Gandure, S., S. Drimie, and M. Faber. 2010. Food security indicators after humanitarian interventions including food aid in Zimbabwe. Food and Nutrition Bulletin 31: 513-523. 
Hendriks, S.L. 2005. The challenges facing empirical estimation of food (in)security in South Africa. Development Southern Africa 22 (1):103-123.

Hendriks, S.L. 2014. Food security in South Africa: Status quo and policy imperatives. Agrekon 53 (2): 1 - 24.

Hendriks, S.L. 2015. The food security continuum: A novel tool for understanding food insecurity as a range of experiences. Food Security (DOI) 10.1007/s12571015-0457-6.

HSRC. 2008. South African Social Attitudes Survey (SASAS). Pretoria: Human Sciences Research Council.

Ingquza Hill Local Municipality. 2013. Integrated development plan review 20142015. Lusikisiki, Eastern Cape, South Africa: Ingquza Hill Local Municipality.

Kennedy, G., T. Ballard, and M.C. Dop. 2011. Guidelines for measuring household and individual dietary diversity. Rome: Nutrition and Consumer Protection Division, Food and Agriculture Organization of the United Nations.

Labadarios, D. 2000. The National Food Consumption Survey (NFCS): Children aged 1-9 years, South Africa, 1999. Stellenbosch: National Food Consumption Survey Consortium, Nutrition Directorate, Department of Health.

Labadarios, D., R. Swart, E.M.W. Maunder, H.S. Kruger, G.J. Gericke, P.M.N. Kuzwayo, et al. 2008. Executive summary of the National Food Consumption Survey Fortification Baseline (NFCS-FB-I) SA, 2005. South African Journal of Clinical Nutrition 21(Suppl. 2): 247-300.

Maxwell, D., and R. Caldwell. 2008. The Coping Strategies Index: Field Methods Manual. Medford: Tufts University, and Atlanta: CARE.

Maxwell, D., B. Vaitla, and J. Coates. 2014. How do indicators of household food insecurity measure up? An empirical comparison from Ethiopia. Food Policy 47:107-116.

Msaki, M.M., and S.L. Hendriks. 2013. Do food quality and food quantity talk the same? Lessons from a household food security study in Embo, South Africa. Journal of the American College of Nutrition 32 (3):165-176.

Msaki, M.M., and S.L. Hendriks. 2014. Measuring household food security using food intake indicators in rural KwaZulu-Natal, South Africa. Ecology of Food and Nutrition 53 (2):193-213. 
Republic of South Africa. 2014. National Policy on Food and Nutrition Security. Government Gazette 590 (37915): 25-44. Pretoria: Government Printer.

Shisana, O., D. Labadarios, T. Rehle, L. Simbayi, K. Zuma, A. Dhansay, P. Reddy, et al. 2013. South African National Health and Nutrition Examination Survey (SANHANES-1). Cape Town: Human Sciences Research Council (HSRC) Press.

Smith, L.C., and L. Haddad. 2015. Reducing child under-nutrition: Past drivers and priorities for the post-MDG era. World Development 68:180-204.

Stats SA. 2003. Sampling methodology for economic statistics. Pretoria: Statistics South Africa.

Stats SA. 2011. Ingquza Hill Fact Sheet. Pretoria: Stats SA.

Stats SA. 2012. GHS Series, volume IV, Food security and agriculture, 2002-2011. Pretoria: Statistics South Africa.

Stats SA. 2014. General Household Survey 2013. Pretoria: Statistics South Africa.

Webb, P., J. Coates, E.A. Frongillo, B. Lorge Rogers, A. Swindale, and P. Bilinsky. 2006. Measuring household food insecurity: Why it's so important and yet so difficult to do. Journal of Nutrition 136:1404S-1408S.

WFP. 2006. Food consumption analysis: Calculation and use of the food consumption score in food security analysis. Rome: World Food Program, Vulnerability Analysis and Mapping Branch (ODAV).

WHO. 2006. BMI classification: Global database on Body Mass Index. World Health Organization. http://apps.who.int/bmi/index.jsp?introPage=intro_3.html

WHO. 2011. Anthro for personal computers: Software for assessing growth and development of the world's children. Version 3.2.2. Geneva: World Health Organization. 